\title{
Research on Post-epidemic Land Stall Economic Policy from the Perspective of Foucault Governance
}

\author{
Wang Yue ${ }^{1, *}$ Wen Aijia ${ }^{2}$, Yu Jianan ${ }^{2}$,Tang Yilin ${ }^{2}$ YYang Qingyi ${ }^{2}$
}

\author{
${ }^{1}$ Northwest University \\ ${ }^{2}$ China University of Geosciences, Wuhan \\ ${ }^{2}$ University of Jinan \\ ${ }^{2}$ Henan Finance University \\ ${ }^{2}$ Sichuan University, School of Public Administration, SCU \\ *Corresponding author. Email: 2653665620@qq.com
}

\begin{abstract}
In the post-epidemic period, the stall economy was once again valued as one of the important supplements to the regular economy. Therefore, it is necessary to adopt reasonable and scientific management methods and policies to avoid the state of "die at one tube, put it in chaos", and become an urgent problem to develop the distribution economy while doing a good job of epidemic prevention and control. This paper selects the policy text of 18 provinces and cities in the post-epidemic period, takes the policy tools as the classification method, the X dimension is the policy tool analysis, uses the policy analysis path of FCA governance, analyzes the contradiction points and enlightenment, and finally proposes the idea of U CINET feedback from the vendors in social network.
\end{abstract}

Keywords : Foucault governance, ground spread economy, post-epidemic, governance.

\section{PREFACE}

\subsection{Background}

Street stall economy refers to an informal economic activity in which individual workers obtain labor income by selling legal commodities in urban public spaces. It can be divided into fixed street vendors and mobile street vendors (without fixed business locations). In particular, the research object of this paper is mobile vendors, and the research problem is fixed vendors. At the beginning of 2020, the COVID-19 epidemic swept across the country. Nearly three months of shutdown led to the closure of a large number of small and medium-sized enterprises and the unemployment of employees, exacerbating the living difficulties of the people at the bottom. In this case, the development of local economy has become an optimal solution for the government to do a good job of economic recovery and development during the epidemic.

It is the result of the special epidemic period and the support from the state that the local economy has become a hot topic in 2020. There are three main research directions in the academic field on the local economy. First, the local economy is analyzed from different perspectives. Such as Li Kunliang's perfect competition perspective; Second, some scholars focus on the development and research of local economy during the epidemic period. Third, the management and influence of the local economy. It can be seen that how to optimize policy text in the future policy design in the postepidemic period has become an important

\section{INTRODUCTION OF REASEARCH MATERIAL AND METHODS}

\subsection{Research Materials}

This article is a compilation of policy documents released by major cities since 2021 to develop the street or night economy. In order to improve the pertinacity and comprehensiveness of the research, the research objects are mainly from the government affairs open proposition in the current open street economy.

columns on the official websites of the people's governments of provincial capital cities or some prefecture-level cities, urban administration and law enforcement bureau and Market Supervision Bureau. Including directly named after the local market economy or content closely related to it and "laws", "regulations", "opinions", "methods", "notices", "plans" and other 
documents reflecting the policy, finally sorted out 18 documents.(See Table 1)

Table 1. 18 Provincial and municipal policy text

\begin{tabular}{|c|c|c|c|}
\hline $\begin{array}{l}\text { Serial } \\
\text { number }\end{array}$ & \multicolumn{2}{|c|}{$\begin{array}{l}\text { Provinces and } \\
\text { cities }\end{array}$} & Policy document title \\
\hline 01 & \multicolumn{2}{|c|}{ Jiangsu Province } & $\begin{array}{l}\text { Implementation Plan of National Urban-Rural Integration } \\
\text { Development Pilot Zone (NingConnecting Area, Jiangsu) }\end{array}$ \\
\hline 02 & \multicolumn{2}{|c|}{$\begin{array}{l}\text { Huanggang City, } \\
\text { Hubei Province }\end{array}$} & $\begin{array}{l}\text { Announcement on the Opening of Temporary Convenience Service } \\
\qquad \text { Points in Urban Areas }\end{array}$ \\
\hline 03 & \multicolumn{2}{|c|}{$\begin{array}{l}\text { Dalian City, } \\
\text { Liaoning Province }\end{array}$} & $\begin{array}{c}\text { Notice on Determining the First Commercial Extreach Areas in Dalian } \\
\text { and Strengthening Management }\end{array}$ \\
\hline 04 & \multicolumn{2}{|c|}{$\begin{array}{c}\text { Shijiazhuang City, } \\
\text { Hebei } \\
\text { Province }\end{array}$} & $\begin{array}{l}\text { The Work Plan on Further Promoting the Development of the Night } \\
\text { Economy }\end{array}$ \\
\hline 05 & \multicolumn{2}{|c|}{$\begin{array}{l}\text { Changchun City, } \\
\text { Jilin Province } \\
\end{array}$} & $\begin{array}{l}\text { Notice on Implementing the Eight Measures to Help Economic } \\
\text { Development in the Field of Urban Management }\end{array}$ \\
\hline 06 & \multicolumn{2}{|c|}{$\begin{array}{l}\text { Chengdu City, } \\
\text { Sichuan } \\
\text { Province }\end{array}$} & $\begin{array}{l}\text { Chengdu Action Plan to Promote Domestic Demand Led by New } \\
\text { Consumption (2020-2022) }\end{array}$ \\
\hline 07 & \multicolumn{2}{|c|}{$\begin{array}{l}\text { Nanchang City, } \\
\text { Jiangxi Province }\end{array}$} & Outline of Nanchang City 14th Five-Year Plan \\
\hline & \multirow[b]{2}{*}{$\begin{array}{l}\text { Shando- ng } \\
\text { Province }\end{array}$} & $\begin{array}{l}\text { Zibo } \\
\text { City }\end{array}$ & $\begin{array}{l}\text { "> Supporting Measures for Implementing the Implementation } \\
\text { Opinions of <Zibo Municipal People's Government on Continuous } \\
\text { and in-depth Optimization of the Business Environment" }\end{array}$ \\
\hline 08 & & $\begin{array}{l}\text { Qing } \\
\text { dao } \\
\text { City }\end{array}$ & $\begin{array}{c}\text { Notice on Responding to the Impact of the Epidemic on Ensuring the } \\
\text { Basic Support of Temporary Public Welfare Posts }\end{array}$ \\
\hline 09 & \multicolumn{2}{|c|}{$\begin{array}{l}\text { Harbin City, } \\
\text { Heilongjiang } \\
\text { Province }\end{array}$} & $\begin{array}{l}\text { Implementation Plan of Harbin City Prosperity Night Economy (2020- } \\
\text { 2022) }\end{array}$ \\
\hline 10 & \multicolumn{2}{|c|}{$\begin{array}{l}\text { Putian City, Fujian } \\
\text { Province }\end{array}$} & $\begin{array}{l}\text { The Three-year Action Plan for Urban Function and Quality } \\
\text { Improvement and Expanding the New Urban Area in Putian City } \\
(2020-2022)\end{array}$ \\
\hline 11 & \multicolumn{2}{|c|}{$\begin{array}{l}\text { Hefei City, Anhui } \\
\text { Province }\end{array}$} & $\begin{array}{l}\text { The Work Plan of Hefei City for Further Optimizing the Business } \\
\text { Environment and Better Serving the Market Subject }\end{array}$ \\
\hline 12 & \multicolumn{2}{|c|}{$\begin{array}{l}\text { Guangzhou City, } \\
\text { Guangdong } \\
\text { Province }\end{array}$} & $\begin{array}{l}\text { Work Plan for Some Regional Businesses (Self-employed) to Take } \\
\text { Temporary Loan during the Normal Epidemic Prevention and } \\
\text { Control Period in Guangzhou }\end{array}$ \\
\hline 13 & \multicolumn{2}{|c|}{$\begin{array}{l}\text { Zhengzhou City, } \\
\text { Henan Province }\end{array}$} & $\begin{array}{l}\text { Opinions on Implementing the Thought of People-centered } \\
\text { Development and Further Improving the Benefit of the People }\end{array}$ \\
\hline
\end{tabular}




\begin{tabular}{|c|c|c|}
\hline 14 & $\begin{array}{l}\text { Liupanshui City, } \\
\text { Guizhou } \\
\text { Province } \\
\end{array}$ & $\begin{array}{l}\text { Notice on Printing and Issuing Ten Measures to Support the } \\
\text { Economic Development of Night Market Economic Night Market }\end{array}$ \\
\hline 15 & $\begin{array}{l}\text { Lanzhou City, } \\
\text { Gansu Province }\end{array}$ & $\begin{array}{c}\text { The Opinions on Actively Responding to the Epidemic and } \\
\text { Effectively Promoting Stable Economic Growth }\end{array}$ \\
\hline 16 & $\begin{array}{l}\text { Ningbo City, } \\
\text { Zhejiang } \\
\text { Province } \\
\end{array}$ & $\begin{array}{c}\text { Notice of the Implementation Plan for Accelerating the Development } \\
\text { of Night Economy in Ningbo City }\end{array}$ \\
\hline 17 & $\begin{array}{l}\text { Qinghai } \\
\text { Province }\end{array}$ & Implementation Plan for "Summer and Autumn Offensive" \\
\hline
\end{tabular}

\subsection{Review and Brief Introduction of The Research Methods}

The policy classification method adopted in this paper is the policy tools[1]. Policy tools refer to a series of means and strategies adopted by policy executors to implement policy programs, solve policy problems, and achieve policy objectives. In the 1980s, the application of policy instruments was developed in the West, and the classification method varied from person to person.

MacDonald divided policy instruments into five types: command, remuneration, function expansion, authority reorganization and advice. This paper adopts the method of Rothwell R[2], according to the actual relationship between actors and policy, dividing the policy into supply, environment and demand-based policy tools.

The supply-oriented policy tool here refers to the measures taken by the government to develop the local distribution economy, such as setting up business areas, improving infrastructure, providing service guarantee, shaping the market and promoting social integration. For example, set up the main business places to carry out the street economy; Guide the street vendors into the dredging points and other standardized places to operate, clear dredging points do not cross the line, do not disturb people, do not use coal and other "eight not" and have a health certificate, have glue "two have" standards. Environmental policy tool refers to a series of external conditions to promote the promotion of local economy policies. For example, encourage innovation, increase publicity, institutional safeguards and flexible law enforcement measures. Specifically include: encourage the innovation of operation mode, to create special commodity stalls operating area. Demanded-type policy tool refers to reducing the blocking force and market risk of policy implementation by lowering the threshold of access, providing financial support, financial support, preferential charges, co-management and cogovernance[3], and promoting the development of local economy. For example, preferential policies should be given to practitioners of local stall economy, and capital investment should be strengthened while lowering the requirements for access, and management should be carried out in coordination with various urban subjects.

The research path used in this paper is Foucault governance. Governance (governmentality) first came from the French College course at Foucault in 1978. In recent years, as Foucault's works and his lectures at the French Academy have been translated into English, his influence has gradually expanded, and the concept of governance has been widely used in the studies of political geography, population geography and social geography. Since the 1990s, Foucault's work has been introduced in China, and the conceptual application of political science, sociology, history and literary criticism to Foucault has increased.[4] The two dimensions of governance technology and governance rationality are the important contents of Foucault governance. The application of scholars has three main topics: ethnic group and life politics, territory and computing, cognition / spatial rationality and urban governance. Traders as the city is an important subject now few results on the study from the perspective of foucault's governance, this paper adopts foucault, governance intraoperative management rationality, management technology, the guide inquiry path (as shown in figure 1), emphasis on guiding research, find the policy and the actual application of conflict points, in order to better serve vendors provide enlightenment to economic development. Here governance rationality refers to the rationality of governance, to justify, with a purpose of the basic principles of governance practices, management technology refers to the management of rational material and operation mechanism, such as patrol, monitoring, data collection, calculation, classification and cartography, geocoding, standardization, etc., the guide of governing inner contradiction between rationality and vendors economy, causing the governance object to disguide behavior. 


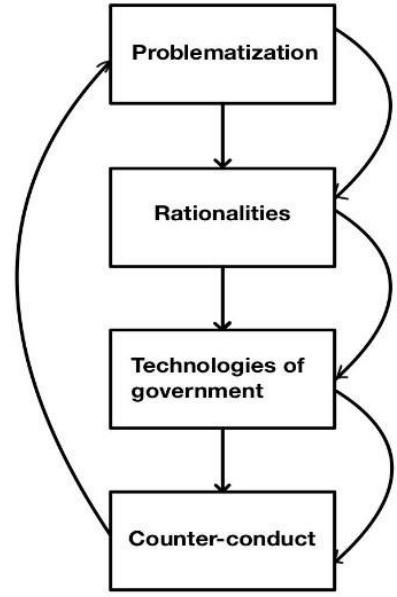

\section{APPLICATION}

This paper first takes the method of Rothwell $\mathrm{R}$ mentioned above as the $\mathrm{X}$ dimension, which is the objective analysis of the two-dimensional structure analysis coordinates. (See Fig. 2)

Figure 1 Foucault governance analysis path

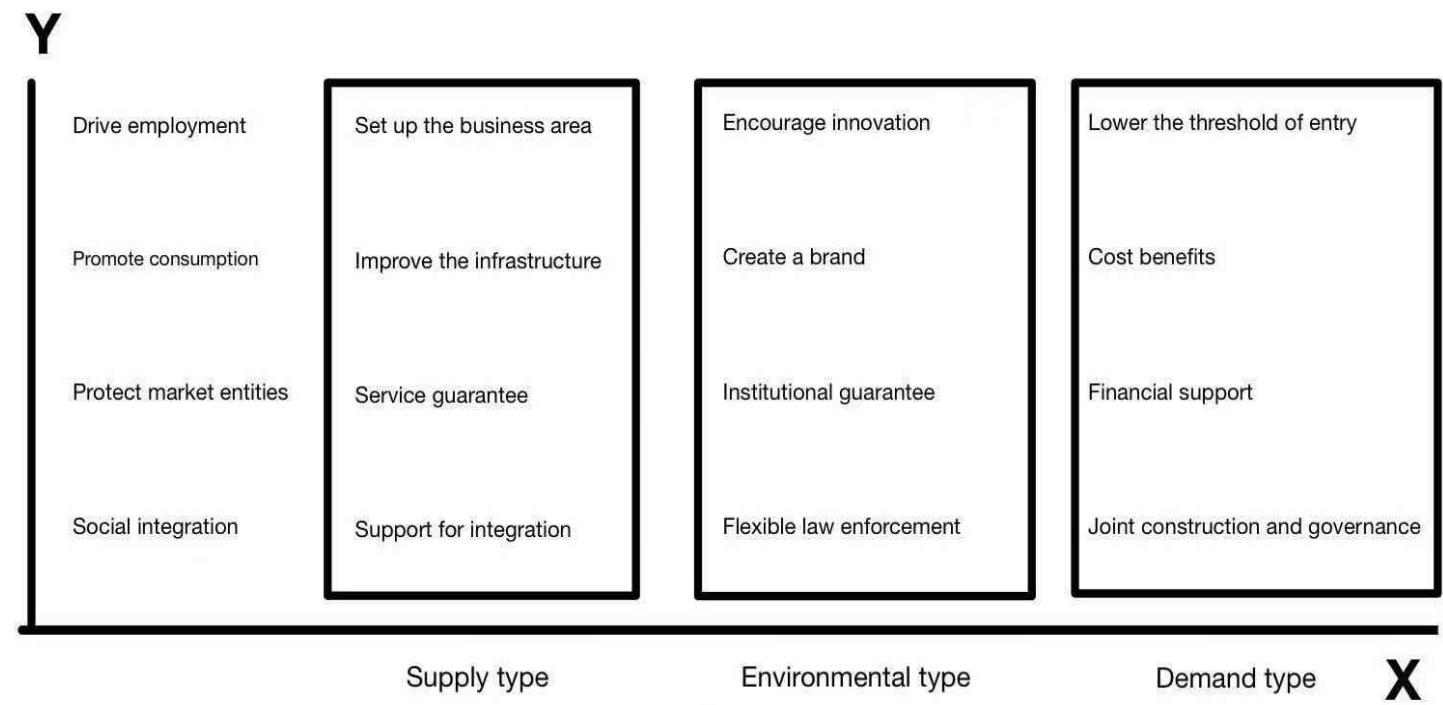

Figure 2 Two-dimensional analysis framework for the policy text

\subsection{Two-dimensional Analysis Framework}

According to the policy of "six stability and six guarantees", this paper divides the $\mathrm{Y}$ dimension into improving employment, driving consumption, protecting market entities and social integration. Increasing the employment rate is the basic requirement of high-quality economic development of "six stability" and "six guarantees"[5], so summarizing this goal as the first goal; driving consumption and maintaining market entities is an important macro way to take proactive response strategies in the post-epidemic era, and a powerful measure to combat the negative economic impact of the epidemic[6], so summarizing this goal as the second goal. Social integration (social inclusion) refers to the process in which individuals cooperate and adapt between individuals, between different groups, or between different cultures. At present, most of foreign research focuses on immigration, including human communication, cultural exchange, etc., and domestic
Research is mainly migrant workers in cities.[7] This concept is put forward by the sociology of empathy of vulnerable groups, and most people engaged in local market economy are local or immigrant with low income. After obtaining employment and income sources, they should also enjoy equal social welfare treatment. Therefore, this paper takes social integration as the ultimate value goal. Based on the above discussion, $\mathrm{X}$ dimension analysis framework is shown in Figure 2.

Later, according to the classification thought of the two-dimensional analysis framework, the content of each policy text was subdivided, concluding that the proportion of supply policy accounts for $61 \%$, environmental policy accounts $28 \%$ and demand policy accounts for $11 \%$. The subdivision of each policy tool type is as shown in Figure 3. It should be noted that this dimension is X dimension. We regard the supply-oriented policy tools, environment-oriented policy tools and demand-based policy tools as the "parent" node, and the "child" nodes of the supply-oriented policy tools are the setting up of business areas, the improvement of infrastructure, service guarantee and support for the integration of itinerant street vendors into the city. 
Encouraging innovation, creating brands, institutional guarantee and flexible law enforcement are the "subnodes" of environment-based policy tools, while lowering the threshold of access, preferential cost,

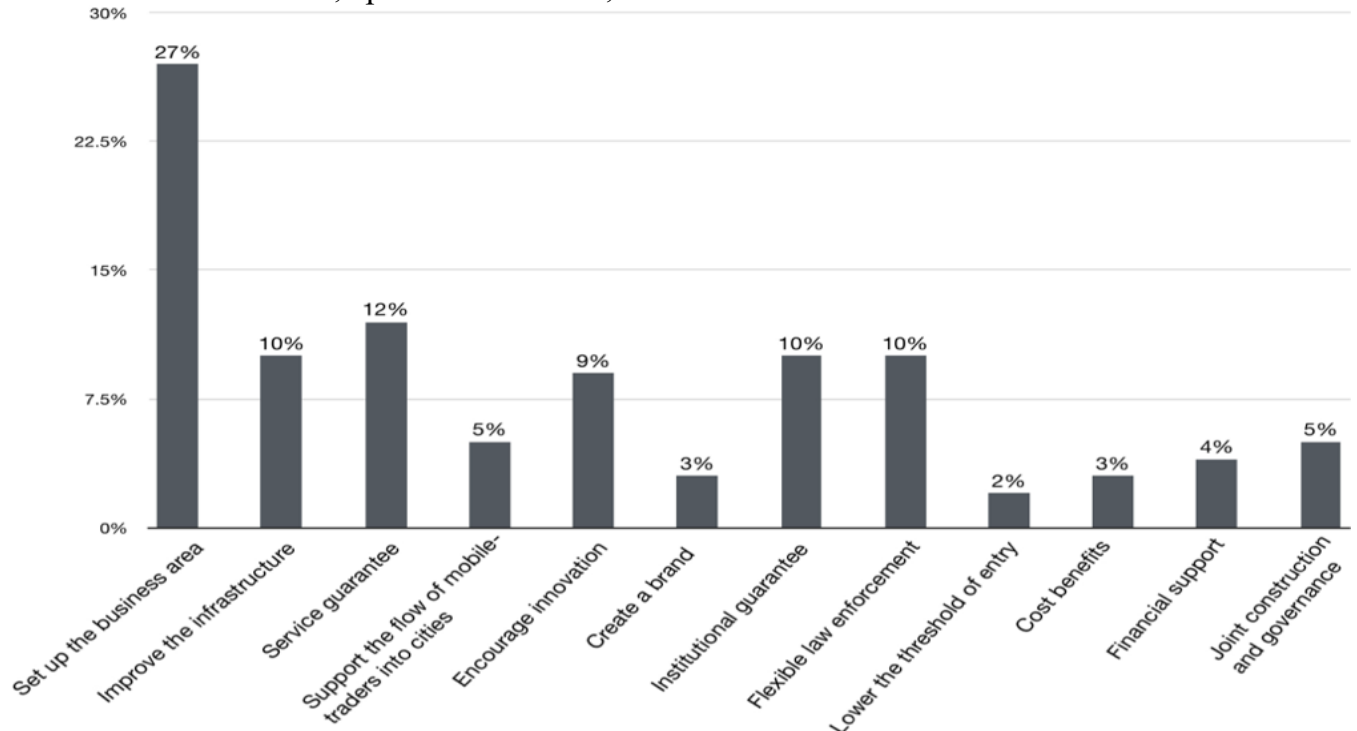

Figure 3 Ground stall economic policy X dimension scale statistics financial support and joint development and joint governance are the "sub-nodes" of demands-based policies.
As the internal policy objectives of different policy types in the $\mathrm{X}$ dimension differ greatly, in order to ensure the accuracy and objectivity of the analysis and avoid overgeneralization, this paper introduces the Ydimension. The $\mathrm{X}-\mathrm{Y}$ dimension analysis results show that: the largest proportion of supply-oriented policy tools, occupying the dominant position. This shows that in the process of promoting the development of local economy, local policy planners are more inclined to open the road for local economy practitioners through direct policies. Environmental policy tool is located in the second place, which encourages innovation and relatively large proportion of using flexible law enforcement, this is because the squatter communities to optimize business environment can be achieved to speed up economic development, the purpose of the mass transfer efficiency, and above target belongs to a higher level of target, need to develop all-round, multi-angle policy support, Only by improving policy matching and policy implementation methods can we achieve the goal. The distribution of demanded-type policy tools in all kinds of objectives is relatively rare, and there is a big gap between the occurrence times of other policy tools. This is because of the particularity of the local economy itself, namely, liquidity, flexibility and autonomy. Therefore, the urgency of policy making in the four value dimensions is low and can be slowed down. The cross-combination analysis of $\mathrm{x}-\mathrm{Y}$ two dimensions is a multi-dimensional dialectical analysis process, which can explain the distribution of policies in different value goals from multiple perspectives, so as to better formulate policies that conform to the practitioners of the local distribution economy. Therefore, the future policy formulation needs to clearly identify the development trend of local economy through preliminary investigation, and formulate different policies under the two-dimensional framework according to the development situation, so as to provide better policy support for the development of local economy.

\subsection{Spective Analysis of Foucault Governance}

\subsection{1. governance rationality and governance technology}

From the perspective of governance rationality and governance technology, all policies were formulated aiming at the actual needs of all provinces and cities at that time, which was reasonable in the governance space.

Supply-based policy tools account for $27 \%$, which is because in the post-epidemic situation, the economy of the ground-sharing needs to relieve the employment pressure. Improving infrastructure $(10 \%)$ and service guarantee $(12 \%)$ are conducive to creating a market atmosphere of land stall economy and providing basic services to operators. There are few policies to support the social integration of mobile vendors $(5 \%)$, because it is a one-way to long-term process from the floating population to becoming local residents, and social integration is also a multi-dimensional concept with rich connotation[8], so the policy ranking comes to the end. Most of the practitioners of the land stall economy are migrant workers, so it is an important proposition between sociology and geography[9] to explore the relationship between new urbanization and informal employment. 
In environmental policy tools, encouraging innovation $(9 \%)$ caters to the trend of integrating the stall economy with emerging growth factors such as the Internet and big data. Although the establishment of brand $(3 \%)$ is limited by multiple factors, Shijiazhuang, Hebei Province and other places make great efforts to build a characteristic brand of land stall economy, and strive to build a reasonable, legal and compliant development pattern of night economy. Institutional safeguards $(10 \%)$ and flexible law enforcement $(10 \%)$ are policy tilted due to the shift of local governments on the stall economy and the transformation of law enforcement methods into flexible and flexible law enforcement.

Demand policy tools are in disproportion state. Among them, lowering the entry threshold (2\%), cost preferential (3\%), financial support

(4\%), co-construction and co-governance (5\%) accounted for a very low proportion. Demand-based policy tools emphasize the cooperation among multiple social subjects. The small proportion of demand-based policy tools indicates that the degree of social cooperation is low. Although the stall economy is an informal economy, it should also be treated rationally and objectively, and it needs to strengthen social coordination, co-management and cogovernance.

\subsection{2. anti-boot (Counter-conduct)}

According to Foucault governance, this paper collects four practical difficulties between policies and vendors in reality.

First, it is the contradiction between product control and sales autonomy. Restricting the types of controlled products is conducive to avoiding excessive competition with regular businesses and maintaining the urban landscape, to some extent depriving vendors of their autonomy to sell products according to market demand. Artificial product types make vendors unable to choose when to sell according to the surrounding market demand and consumer preferences, regularizing the diversion area is faced with the disadvantages that product supply cannot fully meet the market demand. For example, this article once investigated xi'an subway line 2 bell tower exit vendors, one umbrella mobile vendors $\mathrm{Hmentioned} \mathrm{he}$ will generally decide according to the weather, if join the diversion area, signed a contract he want to buy the umbrella, the business has lost the ability to predict the sale of goods, and even increased the business risk.

Second, the gray area of environmental management and the dilemma of the street vendor business field.The establishment of the diversion area is to standardize the operation of street vendors, maintain the urban environment as much as possible, and conduct centralized management to reduce the problem of littering. But inpractice, it seems to play a more role in concentrating garbage into one area. Because many vendors choose food management, it will inevitably produce some kitchen waste. And a largenumber of come to vendors to buy food customers often have littering problem, and these are not business intention and not merchants can control, and the management of channel area is often for each business rather than for customers, resulting channel area environmental management gray, many customers leave a little garbage will make the whole channel area environment dirty, and affect food safety, and whether the surrounding residents or managers often blame environmental problems and vendors, causing conflicts, difficult to effectively solve the problem, but may cause conflict.

Third, the contradiction between urban formal space and informal groups. The setting of the diversion area may attract the rejection of the surrounding formal space around. Although the policy sets the diversion area for standardized management, this also puts forward higher requirements for the actual managers. In the policy practice, there will still be deviations from the planning, such as fire hazards reported in the diversion point, littering affecting the surrounding environment (such as the New Margin diversion point that has been closed). The proximity to formal space by informal groups not conforming to the local environment is vulnerable to exclusion from "indigenous peoples". This contradiction is also not conducive to the mobile vendors to truly gain identity recognition and form a sense of belonging. The protest from the indigenous people is not conducive to the long-term business development of these mobile vendors and even the healthy transformation into the regular economy.

Fourth, the contradiction between epidemic prevention and control and crowd gathering. Mobile vendors gathered in larger areas, and concentrated set booth will intensify crowd gathering to a certain extent, this and epidemic normalized prevention and control to avoid crowd infection, need the government booth distribution and planning, so this will also to a certain extent make business points and large business points, is not conducive to mobile vendors in fixed store of long-term operation, will also limit the actual implementation of the policy, there are still some vendors trying to choose independent mobile operation.

Fifth, the contradiction between fixed and liquidity. One of the characteristics of mobile street vendors is mobility. Before setting up business areas, mobile street vendors can choose goods and business locations according to the changes in the flow of people at different times. At the same time, due to their mobility, fixed costs (such as rent, etc.) can be reduced to 
maximize profits. In essence, the policy of setting up operation areas is to normalize the informal economy and normalize the operation of vendors to maintain the image of the city, which will cause conflicts with the mobility of itinerant vendors. The fixed nature of the business operation model cannot adapt to the flexible and flowing characteristics of the vendors, and it is difficult to find market demand through the "flowing" way. Some itinerant vendors are difficult to maintain their operations under such a mode.

\section{CONCLUSIONS}

In general, the diversion area provides regular business places for mobile traders, which is an important means to guide people and improve the employment rate during the epidemic period, and it is also one of the strategies to promote social integration. We find that governance policies are basically consistent with Foucault 's governance rationality and governance technology, but we find five contradictions from the perspective of anti-guidance of Foucault 's governance technology : contradiction between product control and sales autonomy, the gray area of environmental management and the dilemma of the street vendor business field, the contradiction between urban formal space and informal groups, the contradiction between epidemic prevention and control and crowd gathering, the contradiction between fixed and liquidity. The actual effect of some policy operation deviates from expectations, because the policy text ignores the characteristics of mobile vendors and profit growth elements, and it is far from solving the problem of street vendors only from the "standard standard". And in the post-epidemic era need to play the role of informal economy in promoting economic recovery, for urban vendors governance is more flexible, but cannot let vendors free development, is how in urban governance from the urban image, how to coordinate flow and fixed, regular and informal contradiction is animportant proposition of urban development, also put forward high requirements for urban management. Therefore, in future policy making, it is necessary to adjust the structure of policy use, balance the allocation of various policies among different levels of goals, and improve the coordination of policy use.

In further research on addressing this proposition in the future, this paper suggests that this approach to sociological network analysis can be cited. [10]The actor relationship itself becomes the subject of research. In the research of stall economy, in the future, a policy pilot area can be selected as the research object, using social network theory analysis, code the operators, widely collect their evaluation, behavior, mutual relationship, policy environment and other information, and obtain the analysis data using UCINET.

\section{REFERENCES}

[1] Qu Jie. Research on the Policy Tool for the Reform and Development of Compulsory Education [J]. Fudan Education Forum, 2011,5:11-15.

[2] Rothwell R,ZEGVELD W. Reindusdalization and technology[M]. London: Logman Group Limited,1985;83-104.

[3] Zhang Qian, Wang Wei. Research on sustainable development Strategy of — is based on quantitative analysis of policy texts in 26 provinces and cities [J]. Journal of Kunming University of Technology (Social Science Edition). ,2021,21(04):69-77.

[4] Wang Fulong, Liu Yungang. Governance and Geography: Research Review and Outlook [J]. Human Geography, 2015,30 (05), 1-56.

[5] Pei Changhong. Discussion on the internal connection between "six stability", "six guarantees" and high-quality development [J]. Financial Issues Studies, 2020,10,3-10.

[6] Zhang Youguo, Sun Bowen, Xie Rui. Economic impact decomposition and countermeasures of COVID-19 epidemic [J]. Statistical Studies, 2021,115.

[7] Zhang Wenhong, Lei Spring. Analysis of the structure, status quo and influencing factors of the social integration of urban new immigrants [J]. Sociological Studies, 2008,5,121-145.

[8] Huang Dunping, Wang Gaopan. Empirical Analysis of the Impact of Social Integration on the citizenization of Migrant Workers — Based on the China Mobile Population Dynamic Monitoring Survey in 2016 [J]. Northwest population, 2021,42 (03), 12-22.

[9] Chen Star, Huang Xinvelvet, Huang Gengzhi, Yang Yanshan. New urbanization and informal employment: Scale, Pattern and Social Integration [J]. Geoscience Progress, 2021,40 (01), 52-62

[10] Zhu Guohong: Economic Sociology, Fudan University Press, 1999, p. 348 349 